\title{
ESPACIALIDADE E DESAGREGAÇÃO VOCABULAR NA POESIA: UM POEMA DE E. E. CUMMINGS E SUA TRADUÇÃO POR Augusto De CAmpos
}

\section{Célia Luiza Andrade Prado*}

Resumo: Este trabalho, o cotejo de um poema de e. e. cummings e de sua tradução por Augusto de Campos, pretende mostrar de que maneira a poesia do século XX, que rompe com os padrões tradicionais e valoriza o espaço gráfico obtendo um novo efeito poético com a espacialização e a desagregação vocabular, pode ser traduzida seguindo a proposta teórica dos fundadores do movimento de poesia concreta no Brasil, Haroldo de Campos, Décio Pignatari e Augusto de Campos.

Palavras-chave: Espacialização. Desagregação vocabular. Tradução.

\section{INTRODUÇÃO}

$\mathbf{N}$ a última década do século XIX, a poesia começa a passar por algumas mudanças formais. Cansados de filiação a escolas e ideologias, os poetas resolveram criar seus próprios meios, recursos e técnica, rompendo com os padrões poéticos vigentes. Em oposição aos cânones ritmicos e rímicos surgem os versos livres "como pontos de princípios sobre os quais se assentou uma poética de início da modernidade" (MENEZES, 1991, p. 12).

Essa mudança estética foi inaugurada pelo simbolismo francês, mas não sem polêmica. A crítica maior é de que essas obras não poderiam ser consideradas poesia, pois eram mais "fáceis" de criar. No Brasil, a nova poética se fixou nas primeiras décadas do século XX, entretanto pode-se notar já no século XVIII a produção de versos brancos, como em "A morte de Lindoia" de Basílio da Gama. O verso livre, por sua vez, surge no modernismo, principalmente com Carlos Drummond de Andrade e Manuel Bandeira. Este esclarece que "não basta es- 
crever um trecho em prosa e depois distribuí-lo em linhas irregulares, obedecendo tão somente às pausas do pensamento", mas trata-se sim de "criar o seu ritmo sem auxílio de fora" (BANDEIRA, 1958, p. 1282), mantendo uma importante característica da poesia: a musicalidade. Esses versos, também chamados de versos heterométricos, não seguem um padrão de métrica definido, ou seja, não obedecem às formas fixas, estando, portanto, em oposição aos versos isométricos, de forma regular.

Na obra de Drummond, além dos versos livres, percebem-se alguns tipos de desagregação vocabular. Em muitos de seus poemas, "a fragmentação de palavras sugere, às vezes, a destruição, o desabamento, outras vezes a ideia de fraqueza ou perda de atividade" (CARDOSO, 2005, p. 147), criando também a ambiguidade de sentido. Consequentemente, esse recurso oferece a oportunidade de diferentes leituras e não surpreende o "leitor hábil", mas pode causar estranheza àquele "ingênuo", conforme adverte Mallarmé (2002) no prefácio de Un coup de dés. Esses procedimentos inovadores não são imotivados, tampouco "meros malabarismos circenses com a linguagem" (MENEZES, 1991, p. 10), mas recursos de grande expressividade estilistica.

Após essa ruptura inicial das formas poéticas tradicionais, "esfacela-se o próprio verso enquanto unidade linear de leitura condutora do olho" (MENEZES, 1991, p. 12). As palavras tomam conta de toda a página imprimindo uma visualidade plástica ao texto. Mallarmé (1842-1898), quase no fim da vida, abraça essa nova maneira de fazer poesia dividindo sua obra em duas fases: a simbolista e a espacial. Ao quebrar o verso, o poeta verifica que o espaço em branco da página poderia ser usado não só como simples suporte gráfico, mas também, e principalmente, como material orgânico, como ocorre em Un coup de dés. Para o poeta: "Les 'blancs' en effet, assument l'importance, frappent d'abord; la versification en exigea, comme silence alentour" (MALLARMÉ, 2002, p. 3).

Guillaume Apollinaire (1880-1918) também observa a importância da ruptura com o discurso poético tradicional e adota o "caligrama" - poema cujas linhas ou caracteres gráficos formam uma espécie de pictograma, uma figura relacionada com o conteúdo do texto; palavras soltas e até letras, procurando figurar a ideia central do poema. Campos, Pignatari e Campos (2002, p. 23) apontam essas novas maneiras de expressão lírica como sendo "o limiar de nova poesia" e considera o "novo conceito de composição - uma ciência de arquétipos e estruturas; para um novo conceito de forma - uma ORGANOFORMA".

O aspecto orgânico da obra poética mantém, nesse momento, a sintaxe inalterada, mas, num segundo momento, ela será atingida pela desintegração do verso, reaglutinando as palavras pela sonoridade e reordenando graficamente o espaço. Trilhando esse caminho, no final dos anos 1950, Augusto de Campos, Décio Pignatari e Haroldo de Campos lançam o movimento de poesia concreta, que Menezes (1991, p. 13) considera o "momento de maior alcance da consciência crítica até então produzido pela vanguarda brasileira". No projeto concretista observa-se o entrelaçamento da criação poética com a prática tradutória e com a critica, conforme atesta Haroldo de Campos (2013, p. 207):

1 "De fato, os 'brancos' assumem importância, surpreendem incialmente; a versificação assim exige, como silêncio ao redor". 


\begin{abstract}
Desde os anos 60, iniciei minha reflexão teórica sobre tradução de obra de arte verbal (poesia ou prosa de igual complexidade no plano de expressão; o que em alemão se diz Dichtung). Essa reflexão fundava-se numa prática radical da tradução poética, que vinha sendo levada a efeito por Augusto de Campos, Décio Pignatari e por mim, cujo marco inicial foi a transposição criativa, em equipe, de uma seleção de Cantos de Ezra Pound. Tratava-se, pois, de uma teoria derivada duma prática, que cada vez mais se foi ampliando ao longo do tempo.
\end{abstract}

Além de contribuir para uma nova estética com o concretismo, a tradução de Ezra Pound, e. e. cummings, James Joyce e Stéphane Mallarmé foi peça-chave na divulgação de autores até então desconhecidos no Brasil, contribuindo para a renovação do cânone nacional, a partir de uma visão sincrônica, e do fazer poético: "uma metamorfose vetoriada, de transformação qualitativa, de culturmorfologia: make it new" (CAMPOS; PIGNATARI; CAMPOS, 2006, p. 43).

A verdade é que as "subdivisões prismáticas da Ideia” de Mallarmé, o método ideogrâmico de Pound, a apresentação "verbivocovisual" joyciana e a mímica verbal de Cummings convergem para um novo conceito de composição, para uma nova teoria da forma - uma organoforma - onde noções tradicionais como princípio-meio-fim, silogismo, verso tendem a desaparecer e ser superadas por uma organização poético-gestaltiana, poético-ideogrâmica da estrutura: POESIA CONCRETA.

A categorização dessas novas maneiras de poetar, entretanto, pode ser problemática, pois os conceitos se sobrepõem, e um tipo de poesia pode conter elementos da outra. Contudo, conforme apontam Campos, Pignatari e Campos (2006, p. 95), o sentimento espacial manifesta-se como denominador comum de todas as formas do experimentalismo poético que utilizam "o espaço como elemento substantivo da estrutura poética".

\title{
E. E. CUMMINGS E OS CONCRETISTAS
}

Edward Estlin Cummings (1894-1963) nasceu em Cambridge, Massachusetts, de pais liberais que sempre o encorajaram a desenvolver seus dons artísticos. No fim da Primeira Grande Guerra, Cummings vai a Paris estudar artes plásticas. Em 1924, volta para os Estados Unidos e lança sua primeira coletânea de poesia, Tulips and Chimneys. Cummings estabelece uma rotina que manterá por toda a vida: pintar no período da tarde e escrever à noite.

Os primeiros trabalhos de e. e. cummings incluem poemas de formas tradicionais, mas nos anos 1930 levam o experimentalismo ao extremo com a publicação de No Thanks (1935). A popularidade de e. e. cummings não encontrou respaldo na crítica americana da época. Os críticos de esquerda, da década de 1930, foram os primeiros a considerar seu trabalho como ingênuo tanto no aspecto sentimental quanto no político, e, obviamente, a direita conservadora não o considerava arte. Por outro lado, seus admiradores lhe atribuem valor não só pela sua inovação artística, mas também por suas convicções. 
Na análise de Augusto de Campos (CAMPOS; PIGNATARI; CAMPOS, 2006, p. 38): "os melhores efeitos gráficos de Cummings, almejando uma espécie de sinestesia do movimento, emergem das palavras mesmas, partem de dentro para fora do poema". Muitos de seus poemas possuem, também, uma distribuição não convencional dos versos na página, aparentando pouco ou nenhum sentido, obrigando o leitor a um exercício de decodificação.

O poeta americano ficou mais conhecido pelo estilo não usual de muitos de seus poemas, que incluem a utilização não ortodoxa tanto das letras maiúsculas quanto da pontuação, com as quais, inesperadamente, sem motivo e de forma aparentemente errônea, é capaz de interromper uma frase, ou mesmo palavras individualmente. Como parte da inovação, passa a assinar literariamente "e. e. cummings", com letra minúscula. Para Nilce Sant'Anna Martins (2003, p. 66): "O uso de minúscula no início dos nomes próprios revela rebeldia à tradição, desprezo ao convencionalismo, desejo de chamar a atenção por uma pretensa originalidade". No caso de cummings, o nome assim grafado seria o arauto que anunciaria o percurso de sua estética.

A influência de Cummings, que para Haroldo de Campos pertence à estirpe dos inventores da poesia moderna, no movimento da poesia concreta no Brasil é evidenciada nas 37 referências ao poeta na obra dos irmãos Campos, Augusto e Haroldo, e Decio Pignatari, Teoria da Poesia Concreta, contendo textos críticos e manifestos de 1950 a 1960. Segundo Pignatari (CAMPOS; PIGNATARI; CAMPOS, 2006, p. 90), "os pontos cardeais para a realização de uma poesia concreta são: Mallarmé (Un coup de dés), Pound, Joyce, com sua prosa poética, e Cummings - porque foram esses os que mais se detiveram no problema de estruturação". Augusto de Campos traduziu dez dos mais complexos poemas de e. e. cummings.

\section{TRADUÇÃo DE POESIA}

A tradução de poesia sempre foi motivo de controvérsia. Para muitos, poesia é intraduzivel e a tradução, uma atividade inferior que descaracteriza o original. Paul Valéry afirma que "a qualidade do texto poético é inversamente proporcional a sua traduzibilidade"; para Robert Frost "poesia é o que se perde na tradução" e Voltaire adverte: "lembrai-vos que quando virdes uma tradução, que vedes uma fraca estampa de um belo quadro" (apud ARROJO, 2000, p. 27). Justamente essa dificuldade é que instrumentalizará a tradução na visão de Haroldo de Campos (2004, p. 34): "admitida a tese da impossibilidade em princípio da tradução de textos criativos, parece-nos que esta engendra o corolário da possibilidade, também em princípio, da recriação desses textos”. Dessa maneira, quanto mais intraduzivel for o texto, mais recriável será.

A tradução para Haroldo de Campos é mais que recriação, é transcriação que, com base na semiótica (principalmente no pensamento de Bense e Peirce), tem por objetivo a "reconfiguração no idioma de chegada da forma significante do poema de origem" e não a reconstituição da mensagem. Seria uma tradução voltada à "concretude" do poema, ou seja, aos aspectos sonoros e visuais da palavra em que está incorporado o sentido. O termo verbivocovisual sintetiza essa proposta, também presente na formulação da poesia concreta, que trabalha de maneira integrada o som, o sentido e a visualidade das palavras. 
Destarte, tradução e criação poética estariam intimamente ligadas, estando as duas em pé de igualdade e em constante interação, num contínuo e mútuo enriquecimento entre texto original e texto traduzido. Consequentemente, o trabalho de tradutor, por ser tributário da atividade primeira (a de poeta), não é secundário, pois é também criativo, havendo uma interdependência produtiva entre o fazer poético e o traduzir. Assim sendo, o poeta leva vantagem sobre o não poeta no que diz respeito à atividade de tradutor, porque o poeta é mais apto a transcriar.

Dada a necessidade de diferenciar essa proposta de tradução daquelas tradicionais que corroboram o aspecto de fidelidade servil, Haroldo de Campos (1983, p. 60) adota o termo isomorfismo, emprestado da cristalografia: em que original e tradução "serão diferentes enquanto linguagem, mas, como corpos isomorfos, cristalizar-se-ão dentro de um mesmo sistema", posteriormente, substituindo-o por paramorfismo.

Central na sua teoria acha-se a reflexão de Fabri de que a obra de arte verbal não é além de sua própria estrutura, pois "é impossível distinguir entre representação e representado" (CAMPOS, 2004, p. 31). Complementando essa reflexão, Haroldo de Campos considera como princípio fundamental para tradução o conceito de função poética de Roman Jakobson:

Na tradução de um poema, o essencial não é a reconstituição da mensagem, mas a reconstituição do sistema de signos em que está incorporada esta mensagem, da informação estética, não da informação meramente semântica (CAMPOS, 1977, p. 100).

Assim, na tradução da poesia de e. e. cummings, deve-se levar em conta que ela dialoga com as artes visuais, apagando as fronteiras entre texto e imagem e aproximando diferentes manifestações artísticas, apresentando o poema de maneira gráfico-espacial.

Poetas se conscientizaram da visualidade da escrita e da página, além de incorporar elementos gráficos e imagens aos seus trabalhos. Artistas visuais retomaram a origem visual da escrita, utilizando elementos textuais em suas obras: grafismos, letras de diversos alfabetos, colagem de fragmentos de textos impressos etc., utilizando a escrita como elemento gráfico e/ou conceitual (VENEROSO, 2000).

Quanto a isso também concorda Augusto de Campos, cuja concepção de poesia está profundamente vinculada às artes visuais e à música, e o primeiro passo no processo criativo é projetar o poema no espaço, materializá-lo graficamente, e armar a sua "constelação sonora". Consequentemente, são poemas para serem vistos e ouvidos, exigindo do espectador/leitor um exercício de decodificação para que o sentido vá se formando sutil e gradualmente na mente. Esse tradutor/poeta se propunha a traduzir somente aquilo que considerava culturalmente revolucionário, e seu interesse pela poesia de cummings vai ao encontro de sua prática tradutória inovadora.

Para compor Grasshopper, e. e. cummings, além da espacialização da estrutura do poema, lança mão de recursos gráficos como a desagregação vocabular, 
a utilização de letras minúsculas e maiúsculas, e da pontuação, de maneira não convencional e da onomatopéia. A "nova” poesia busca a fusão conceitual da imagem com a palavra. A tradução dessa poesia visual impõe o desafio ao tradutor de recriar o espaço gráfico da obra de partida segundo uma distribuição única, a fim de recompor uma imagem figurativa.

Haroldo de Campos (2004, p. 43) considera que o aspecto "ótico" do poema deve ser traduzido, "seja quanto à disposição tipográfica, seja quanto à fragmentação e às relações interlineares". Essa atenção à "concretude" do poema implica a correspondência do número de letras e "das coincidências físicas (plásticas e acústicas)".

\section{GRASSHOPPER E A TRADUÇÃO}

A tradução de Grasshopper por Augusto de Campos foi originariamente publicada no Diário de São Paulo, em 3.7.1955, e republicado no Correio da Manhã do Rio de Janeiro em 28.4.1956. Em 1960, sairia a primeira edição dos dez primeiros poemas (pelo Serviço de Documentação do Ministério da Educação e Cultura com o apoio de Simeão Leal e Oliveira Bastos). Por sua vez, a tradução de - 40 Poem(a)s, editada pela Brasiliense, é seu último trabalho com esse poeta americano.

Ao colocar lado a lado o poema de Cummings e a tradução de Augusto de Campos, nota-se de imediato que a distribuição gráfica dos dois poemas se assemelha muito. Nota-se claramente a quebra da linearidade do verso: as palavras e os fonemas se decompõem e se recompõem, a pontuação é desordenada e as maiúsculas são intercaladas com as minúsculas.

Enquanto o leitor busca desembaralhar as sílabas e letras, sua mente vai gradualmente construindo as conexões até decifrar a mensagem: "Grasshopper, who, as we look now, upgathering leaps, arriving to become, rearrangingly, grasshopper" e na tradução: "Gafanhoto, que, se eu olho para o alto, reunindo-se num salto, ele salta, chegando a recompor-se, tornando-se gafanhoto". Entretanto, a mensagem só se realiza enquanto "informação estética" em sua relação com a desagregação vocabular e a espacialização. 
Figura 1 - Texto-fonte e texto-alvo

$$
\text { r-p-o-p-h-e-s-s-a-g-r }
$$

who

a)s w(e loo)k

upnowgath

PPEGORHRASS

eringin(o-

aThe):1

eA

Ip:

$\mathrm{S}$

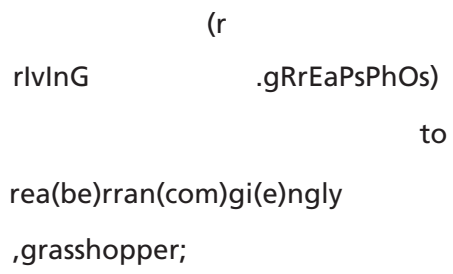

a

to o-h-o-t-n-a-f-g-a

que

s)e e(u olh)o

paraoaltor

HOTGOAFAN

eunindose(n-

umEle:s

$\mathrm{aL}$

It

A

(h

eGaNdO

recom(tor)pon(n)d(ar-se)o

,gafanhoto

Fonte: Campos, Pignatari e Campos (2006).

A disposição das palavras que recobre toda página forma um sentido geral da imagem do gafanhoto saltando, se desintegrando e se recompondo. Esse efeito é produzido em parte pelo fato de as sílabas de "grasshopper/gafanhoto" serem rearranjadas quatro vezes terminando com a grafia normal. As letras embaralhadas de "grasshopper/gafanhoto" nas duas primeiras ocorrências (linhas 1 e 5), por dificultarem a decodificação da palavra, remetem à camuflagem do inseto na grama. Na sequência, o inseto, até então escondido e imóvel, dá um salto enérgico ainda não revelando sua identidade (linha 12), que só será percebida no descanso (linha 15).

No poema, a leitura principia na esquerda, seguindo obliquamente para a direita, depois horizontalmente para a esquerda, e assim sucessivamente numa dinâmica às vezes interrompida por uma pontuação, uma letra maiúscula, um parêntese. Essa espacialização revela a mensagem de maneira "ideogramática", sugerindo mais o "quadro" do que a descrição da ação.

A distribuição dos parênteses permite diferentes leituras com a inclusão ou exclusão de palavras, assim como a pontuação, aparentemente aleatória, cria ambiguidade propiciando várias leituras. Poderiamos considerar um poema sem título ou cujo título fosse "r-p-o-p-h-e-s-s-a-g-r", na primeira linha. Mas também seria possivel que o título "The Grasshopper" tenha se desagregado ficando o artigo definido The na linha 7 e grasshopper "saltado" para a última (NÄNNY, 1985).

Haroldo de Campos, todavia, parece não interpretar dessa maneira e no lugar de The coloca o pronome Ele. A escolha, além da equivalência em número de letras que o pronome pessoal tem com o artigo definido em inglês criando uma se- 
melhança visual e que não existiria se a decisão fosse pelo equivalente gramatical com o artigo definido masculino em português, há uma intenção de dar ênfase à ação. Com o pronome ele como sujeito de reunindo-se num salto, o tradutor procura compensar por meio da redundância "reunindo-se num salto ele salta" a ausência da sensação de agilidade que a palavra gafanhoto sugere, mas que está presente na sonoridade e na própria constituição da palavra grasshopper.

No vocábulo gafanhoto, a vogal posterior [ô] "sugere ideias de fechamento, redondeza e escuridão" e associada à ressonância nasal evoca "distância, lentidão, moleza” (MARTINS, 2003, p. 33). Por sua vez, grasshopper (literalmente gafanhoto) é uma palavra composta por grass (grama) com a vogal [a] que amplifica o som sibilante do duplo [s] e hopper (saltador), cuja oclusiva bilabial sugere um movimento brusco, como uma explosão. A sonoridade de grasshopper possui um valor onomatopaico que fica mais evidente no embaralhamento e inversão de suas letras, evidenciando as consoantes [r], [s] e [gr], durante todo o poema, imitando o chichiar, ziziar, do gafanhoto. De certa maneira, Augusto de Campos recupera o som do gafanhoto nas aliterações do [r] e [s] em reunindo-se, recompondo-se, tornando-se, salto, salta.

Contudo, vale ressaltar que a intenção primeira da poesia espacializada é de natureza mais visual que sonora. O poema tem por princípio trabalhar com as palavras no seu aspecto visual, resultando numa criação artística singular; aproximar a poesia das artes plásticas, sem ignorar completamente o seu parentesco com a música.

\section{CONSIDERAÇóES FINAIS}

A desorganização aparente é fruto de um rigor na construção do poema, pois "o que importa não é o que dizer e sim como dizer" (CARDOSO, 2004, p. 148). A comunicação na poesia espacializada pressupõe um exercício intelectual na busca da relação visual com o significado. O problema de decodificação é um efeito intencional, quase lúdico, provocado pelo inusitado e a desagregação gráfica gera novas combinações de sentido. O efeito expressivo que é provocado pelo imprevisível só se presta nesse momento específico. A criação de uma obra poética dessa natureza tem a intenção de provocar uma experiência singular, uma vez que o desvio intencional da forma padrão é caracterizado pela expressividade.

O poema Grasshopper é uma descrição de uma ação, evidenciando pela desagregação vocabular todos os seus momentos: o início do salto, o voo e a aterrissagem, percebidos de maneira simultânea e não linear. Todos esses aspectos acham-se na tradução de Augusto de Campos à exceção do efeito onomatopaico da palavra grasshopper. A sonoridade, todavia, não é o aspecto primordial da poesia espacializada. Além disso, trata-se de um procedimento usual no processo tradutório, que, quando ocorre uma perda, frequentemente imposta pela particularidade de cada lingua, compensa-se em outro ponto ou por meio de outro recurso. A perda ocasional de um elemento em um ponto da tradução pode ser compensada por seu aparecimento em algum outro ponto adequado. Esse procedimento de compensações faz o efeito, no caso poético, incidir não exatamente nos mesmos pontos e não necessariamente por meio dos mesmos processos.

A reconfiguração dos elementos formais no idioma de chegada implica não só um exercício criativo e inventivo, mas também uma leitura crítica dos aspectos que 
caracterizam e conferem expressividade ao texto fonte. Augusto de Campos buscava uma nova informação estética obtida via tradução, que seria "operacionalmente distinta da tradução propriamente dita (adequada às mensagens a dominante cognitiva, comunicativo-referencial)" (CAMPOS, 1989, p. 82). A tradução do poema de Cummings é mais que uma recriação, é criação paralela, é paramorfismo.

\section{SPATIALity AND Vocable disAgGREgation In POETRY: A POEM BY E. E. CUMMings AND its translation by Augusto de Campos}

Abstract: This paper shows how the 20th century poetry, in opposition to the traditional canonical forms, increases the value of graphic using the space and vocable desaggregation in an attempt to create art as a single experience and how it can pose a challenge to translation, by contrastive analysis of a poem by e.e.cummings and its translation by Augusto de Campos, following the theoretical approach of the founders of the movimento da poesia concreta, Haroldo de Campos, Deciio Pignatari and Augusto de Campos.

Keywords: Spatialization. Vocable desaggregation. Translation.

\section{REFERÊNCIAS}

ARROJO, R. Oficina da tradução. São Paulo: Ática, 2000.

BANDEIRA, M. Poesia e prosa. Rio de Janeiro: José Aguilar, 1958. v. 2.

CAMPOS, A. de. Entrevista. Disponivel em: <http://www2.uol.com.br/augustodecampos.htm>. Acesso em: 21 mar. 2017.

CAMPOS, A. de; PIGNATARI, D.; CAMPOS, H. de. Mallarmé. 3. ed. São Paulo: Perspectiva, 2002.

CAMPOS, A. de; PIGNATARI, D.; CAMPOS, H. de. Teoria da poesia concreta. 4. ed. São Paulo: Ateliê, 2006.

CAMPOS, H. de. A arte no horizonte do provável. 4. ed. São Paulo: Perspectiva, 1977.

CAMPOS, H. de. Da tradução à transficcionalidade. Letras, São Paulo, n. 3, p. 82-107, 1989.

CAMPOS, H. de. Metalinguagem e outras metas. 4. ed. São Paulo: Perspectiva, 2004.

CAMPos, H. de. Transcriação. Org. Marcelo Tápia. São Paulo: Perspectiva, 2013.

CARDOSO, E. A. A criação neológica estilística. Matraga: Revista do Programa de Pós-Graduação em Letras, Rio de Janeiro, v. 16, p. 105-118, 2004.

CARDOSO, E. A. A desagregação vocabular: um processo lingüístico. Estudos Lingüísticos, Campinas, v. XXXIV, p. 147-152, 2005. Disponivel em: <http:// ww.gel.org.br>. Acesso em: 13 set. 2014. 
MALlARMÉ, S. Préface. In: CAMPOS, A. de; PIGNATARI, D.; CAMPOS, H. de. Mallarmé. 3. ed. São Paulo: Perspectiva, 2002.

MARTINS, N. S.'A. Introdução à estilística. 3. ed. São Paulo: T. A. Queiroz, 2003. MENEZES, P. Poética e visualidade: uma trajetória da poesia brasileira contemporânea. Campinas: Editora da Unicamp, 1991.

NÄNNY, M. Iconic Dimensions in Poetry. In: WASWO, R. (Ed.). On Poetry and Poetics. S. 1.: Gunter Narr Verlag, 1985. Disponivel em: <http://www.english. uiuc.edu/maps/poets/a_f/cummings/cummings.htm>. Acesso em: 25 out. 2017.

VENEROSO, M. do C. de F. Caligrafias e escrituras: diálogo e intertexto no processo escritural nas artes do século XX. 2000. Tese (Doutorado em Literatura Comparada)-Faculdade de Letras, Universidade Federal de Minas Gerais, Belo Horizonte, 2000.

Recebido em setembro de 2017. Aprovado em setembro de 2017. 